\title{
Turistando CG
}

\author{
Annie Muzzi B. de Lamare \\ Paz \\ Inst. Federal de Mato Grosso do \\ Sul \\ Campo Grande, MS, Brasil \\ annie.paz@estudante.ifms.edu.br
}

\author{
Laíza Santos Sá \\ Inst. Federal de Mato Grosso do \\ $\mathrm{Sul}$ \\ Campo Grande, MS, Brasil \\ laiza.sa@estudante.ifms.edu.br
}

\author{
Luiz Fernando Delboni \\ Lomba \\ Inst. Federal de Mato Grosso do \\ $\mathrm{Sul}$ \\ Campo Grande, MS, Brasil \\ luiz.lomba@ifms.edu.br
}

\begin{abstract}
It is known that Brazil is a country with great tourism potential, due to its enormous cultural and natural diversity. However, this potential is not fully exploited, as observed in the city of Campo Grande. Even located on the route of the main tourist attractions of the state of Mato Grosso do Sul, the city is not recognized for its tourist attractions. Having knowledge of this scenario, brings the proposal of Turistando CG, with the objective of disseminating the tourist activities of Campo Grande, from a tourist inventory built to feed a web system, developed to disseminate the data of tourist activities.
\end{abstract}

\section{KEYWORDS}

Tourism, Tourist Inventory, Joomla

\section{INTRODUÇÃO}

O Brasil é um país com um grande potencial turístico devido a enorme diversidade cultural e natural presente em seu vasto território. Segundo o Ministério do Turismo, em 2017, o turismo gerou aproximadamente U\$ 163 bilhões (cento e sessenta e três bilhões de dólares) para a economia, representando cerca de 7,9d do PIB nacional [1].

Apesar do valor representativo do PIB, o Brasil aparece apenas em $32^{\circ}$ no ranking que classifica 140 países em seus pontos fortes relativos ao Turismo [2].

O estado de Mato Grosso do Sul possui sua economia voltada para o agronegócio, porém, atualmente cresce turisticamente em decorrência das várias belezas naturais presentes na região da Serra da Bodoquena e do Complexo do Pantanal.

A capital do estado, Campo Grande, não está entre os principais pontos turísticos do mesmo, apesar de ocupar uma posição geograficamente privilegiada, no centro do estado, que é rota obrigatória para os turistas que se destinam às demais cidades turísticas de Mato Grosso do Sul.

Com o objetivo de fomentar o turismo em Campo Grande, este trabalho teve como objetivo desenvolver uma plataforma web para divulgação dos dados turísticos da cidade e construir um inventário turístico, para divulgar suas informações.

\section{METODOLOGIA}

O desenvolvimento do trabalho foi dividido em duas partes principais, sendo elas a elaboração de um inventário turístico e o desenvolvimento de uma plataforma web para divulgação das informações e dados turísticos da cidade de Campo Grande.

\subsection{Inventário Turístico}

O inventário é imprescindível neste trabalho, visto que nele estão contidas as informações necessárias para alimentar a plataforma web. Para o seu desenvolvimento foi necessário categorizar os pon- tos turísticos da cidade, que foram classificados a partir da análise dos dados existentes nos documentos disponibilizados pela Secreta- ria Municipal de Cultura e Turismo de Campo Grande (SECTUR) em seu site oficial [3].

Além da análise dos documentos oficiais do município, foi desenvolvido e aplicado um questionário para identificar a percepção e a experiência da população com o turismo na cidade. O questionário foi elaborado na plataforma Google Forms, divulgado no dia 6 de junho de 2019, nas redes sociais Facebook e Whatsapp, na linha do tempo e no "story", sendo finalizado no dia 21 de junho de 2019, totalizando a participação de 100 pessoas.

Os participantes responderam a sete perguntas (questões abertas para não induzir a resposta), que perguntavam sobre quais os pontos da cidade de sua preferência, categorizados em pontos gastronômicos, culturais e de lazer, e quais os itens de destaque da cidade que o turista não pode deixar de conhecer/experimentar.

Para a escrita do inventário turístico foi conferida a veracidade dos dados expostos nos documentos da SECTUR, validando se as informações inseridas estavam atualizadas (se os locais ainda estavam em funcionamento e o horário de atendimento) e avaliado se os pontos citados no questionário estavam nestes documentos. Os locais que não estavam, foram adicionados ao inventário.

\subsection{Plataforma Web}

Para definição dos requisitos para a plataforma, foram avaliados sites turísticos já existentes em outras cidades, tais como Rio de Janeiro, Fernando de Noronha, Bariloche (Argentina) e Comodoro Rivadavia (Argentina). As características semelhantes e os diferenciais apresentados por eles foram tidos como de suma importância para a composição dos requisitos do Turistando CG.

A partir dos requisitos foram definidas as funcionalidades do sistema. As principais opções do sistema são a busca por pontos turísticos e a consulta por dados de mobilidade. Os pontos 
turísticos foram categorizados e o gerenciamento deles pode ser feito exclusivamente pelo usuário administrador.

A Figura 1 apresenta o diagrama de caso de uso, com as funcionalidades apresentadas pelo Turistando CG.

No processo de modelagem e documentação dos requisitos identificou-se que a proposta trata-se de um site com um sistema gerenciador de conteúdo (CMS - Content Management System). Partindo desse pressuposto, foi escolhido o Joomla como o sistema para desenvolvimento da plataforma.

O Joomla é um sistema de gerenciamento de conteúdo, de código aberto e gratuito, desenvolvido em PHP, com base de dados MySQL, e com estrutura MVC (model-view-controller), que permite integrar outras aplicações além dos recursos CMS fornecidos [4].

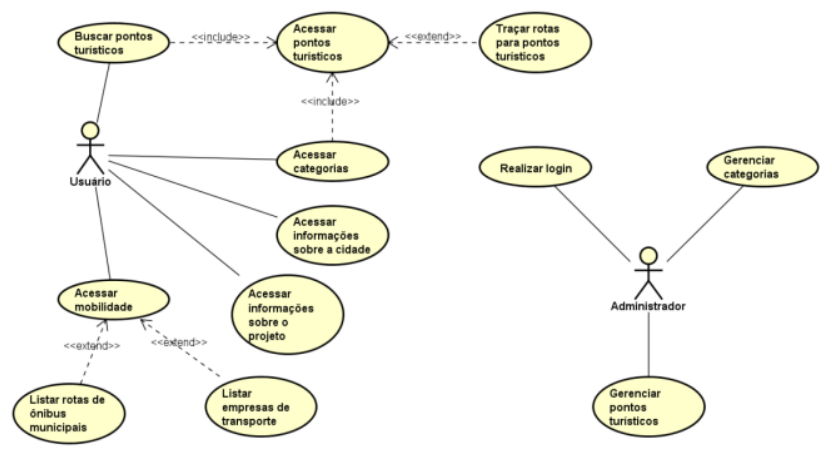

Figure 1: Diagrama de caso de uso do Turistando CG

\section{RESULTADOS E DISCUSÕES}

O referido trabalho cumpre com seus objetivos e apresenta como resultado a plataforma web, alimentada a partir dos dados obtidos no inventário e a análise quantitativa e qualitativa do questionário aplicado.

\subsection{Inventário Turístico}

Os dados obtidos a partir da investigação realizada junto à comunidade foram avaliados. Os pontos turísticos foram organizados em cinco categorias: Gastronomia, Cultura, Lazer, Geral e Identidade Local.

Os dados da categoria Identidade Local, apresentado na Figura 2, foi proposto para identificar as características marcantes da cidade, segundo a comunidade. O Tereré foi o item mais citado, com mais de 46a das respostas. O resultado não foi surpreendente, tendo em vista que a bebida é típica da região. A mesma é feita com a infusão da erva-mate de origem Guarani, e consumido com água gelada, o que o torna uma bebida refrescante, e por tal motivo é apreciado pela população, considerando o clima predominantemente quente da cidade.

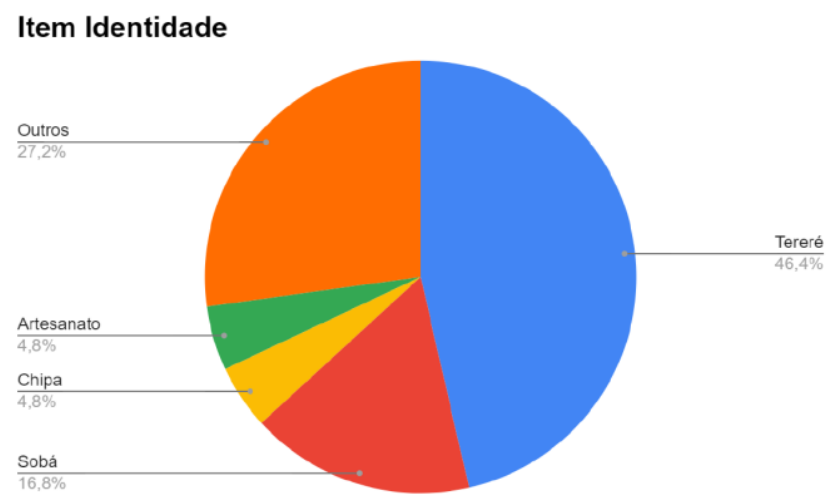

Figure 2. Resultado da categoria Identidade Local

É importante destacar os itens que tiveram menos respostas (e estão agrupados no item Outros), tendo em vista que são características marcantes da cidade, segundo a comunidade, e que o turista não deve deixar de experimentar. Os itens como menos respostas foram: Sopa Paraguaia, Peixe, Ervas Regionais e Pastel de Jacaré. Ressaltamos este fato, pois as respostas do questionário eram espontâneas, sem opções de escolha para o participante.

Também destacamos os pontos turísticos considerados mais populares, como mostra o gráfico da Figura 5. O local de destaque foi o Parque das Nações Indígenas, que já era esperado, visto que o parque é o ponto turístico mais frequentado da cidade, inclusive pela população local. O item Outros apresenta o agrupamento dos pontos que obtiveram menos respostas.

Geral

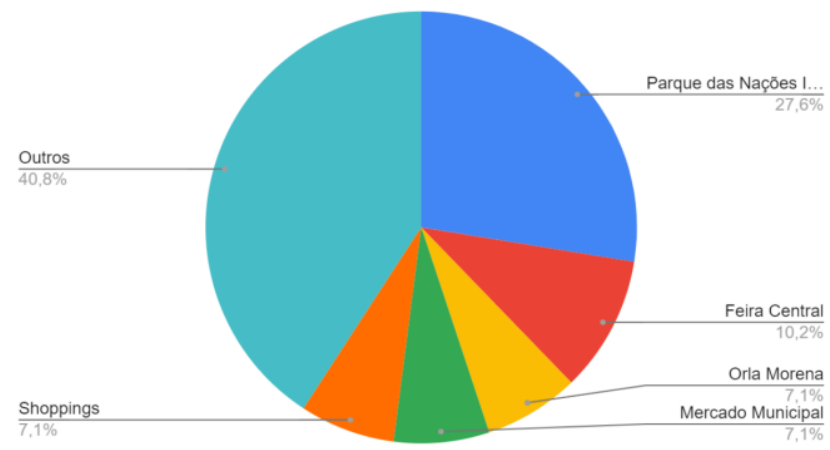

Figure 3. Resultado da categoria Pontos Turísticos

Avaliando os resultados é possível identificar que a maioria das respostas estão agrupadas no item Outros, mostrando a diversidade de respostas recebidas. Esta diversidade reforça a importância de investimentos em outros pontos turísticos da cidade, a fim de fomentar o turismo.

Ademais, é de grande valia destacar os pontos turísticos gerais com menor porcentagem de respostas, que apesar da pouca visibilidade apresentam um potencial turístico interessante. São eles: Lagoa Itatiaia, Morro do Ernesto e Morada dos Baís. 


\subsection{Plataforma Web}

Para a implantação do Turistando CG foi utilizado o servidor online CloudAccess.net, disponibilizado pelo gerenciador de conteúdo Joomla, que hospeda e fornece suporte gratuitamente. A url para visualização da plataforma é a https://turistandocg.joom1a.com.

A Figura 4 apresenta a tela inicial do site, na qual contém o menu de navegação, sendo eles: "Inicio", que apresenta submenus com os núcleos turísticos, "Sobre CG", onde é apresentada a cidade de Campo Grande, "Quem somos" e "Mobilidade", que auxilia o visitante em sua locomoção para chegar até a cidade e no uso do serviço de transporte público. Também há um carrossel de imagens, contendo quatro paisagens que realçam a beleza da cidade.

Ainda na tela inicial, abaixo do carrossel, estão listadas as categorias turísticas disponíveis para consulta: Gastronomia, Histórico Cultural, Hotelaria, Ambiente Rural, Natureza e Birdwatching, Turismo de Compras, Marcos e Monumentos e Negócios e Eventos, como mostra a Figura 5. Ao clicar na imagem de qualquer categoria,

o usuário é direcionado para a listagem de pontos turísticos do segmento.
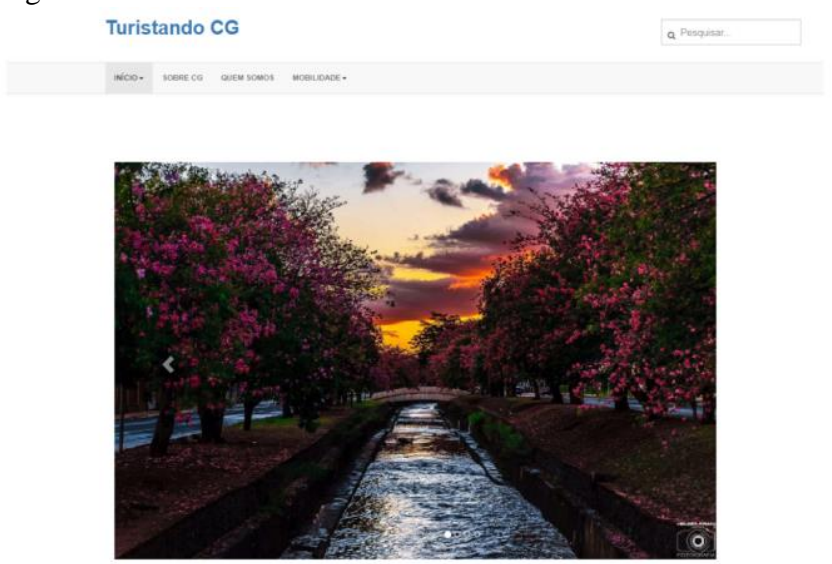

Figure 4. Tela inicial do Turistando CG
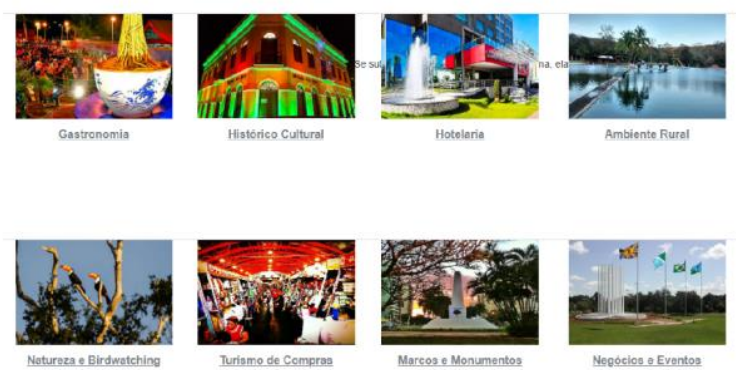

Figure 5. Categorias disponíveis na tela inicial
Como disposto na Figura 6, após clicar em um ponto turístico específico, o usuário acessa as informações do mesmo.

Turistando CG

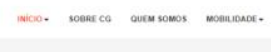

S

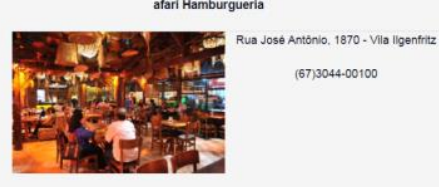

Figure 6. Exemplo de ponto turístico acessado

\section{CONSIDERAÇÕES FINAIS}

Atualmente o trabalho está em fase de finalização das funcionalidades da plataforma e de validação e inserção das informações turísticas identificadas.

Espera-se que esta iniciativa fomente um maior engajamento público para promoção do turismo em Campo Grande, possibilitando a formalização de parcerias econômicas para divulgação da plataforma, além da aproximação com a SECTUR.

Além disso, é imprescindível a atualização periódica dos pontos turísticos, tais como suas respectivas informações, e também, implementar uma área de avaliações aos pontos turísticos, a qual poderá apontar possíveis melhorias ao sistema também. Na categoria Mobilidade, pode-se implementar recursos que permita a interação direta entre o usuário e os sites das companhias aéreas e rodoviárias, para a compra de passagens.

\section{REFERÊNCIAS}

[1] Ministério do Turismo. Turismo injetou us\$ 163 bilhões no brasil em 2017 2018. URL < http://www.turismo.gov.br/\%C3\%BAltimas-not $\%$ C3\% ADcias/11037-turismo-injetou-us $\backslash$ protect $\backslash \mathrm{T} 1 \backslash$ textdollar-163bilh\%C3\%B5es-no-brasil-em-2017.html>.

[2] Marcos Martins. Brasil é o $32^{\circ}$ país mais competitivo no turismo. 2019, september 2019. URL https://www.panrotas.com.br/mercado/pesquisaseestatisticas/2019/09/brasil-e-o-32o-pais-mais-competitivo-no-turismovejaranking_167371.html.

[3] SECTUR. Secretaria municipal de cultura e turismo, 2019. URL http://www.campogrande.ms.gov.br/sectur/.

[4] Joomla. Joomla content management system, 2020. URL https://www.joomla.org/. 